\title{
A Standardized Abundance Index from Fishery Independent Data: A Case Study of Swordfish (Xiphias Gladius) from Indonesian Tuna Longline Fishery
}

\author{
Bram Setyadji*, and Zulkarnaen Fahmi \\ Research Institute for Tuna Fisheries, Denpasar, Bali, Indonesia - 80224
}

\begin{abstract}
Most varieties of the billfish caught in the Indian Ocean are either swordfish or Indo-Pacific sailfish. Swordfish is mostly considered as by-catch from tuna longline fisheries, except for South African, Spanish and Portuguese fleets. Despite of its importance, little are known about their abundance. Relative abundance indices are the input data for stock assessment analyses that provide useful information for decision making and fishery management. In this paper, a Generalized Linear Model (GLM) was utilized to systematize the catch-per-unit-effort (CPUE) and to estimate relative abundance indices based on the Indonesian longline dataset. The data was collected by scientific observers from August 2005 to December 2016. Conventional models for counting data were used, but zero-inflated and hurdle models also considered, due to the high number of zero-catchper-set. Akaike Information Criterion (AIC) and Bayesian Information Criterion (BIC) were applied to select the best models among all those evaluated. Both AIC and BIC suggested that the simple negative binomial (NB) model is the best option. The trends were relatively similar to the nominal series, but with smoother peaks. In general, there was a tendency of positive trends in the last decade, with the series varying throughout the period.
\end{abstract}

\section{Introduction}

Swordfish (Xiphias gladius) is a large oceanic apex predator inhabits all the world's oceans. It is predominantly known as a subject of exploitation worldwide, mainly in the Pacific Ocean, Atlantic Ocean, and Mediterranean Sea [1]. Throughout the Indian Ocean, swordfish are primarily caught by longline fisheries, and the commercial harvest was first recorded by the Japanese in the early 1950s as bycatch of their tuna longline fisheries [2]. Since 1990s the catches of swordfish increased sharply to a peak of 35,000 tons in 1998 [2] due to the growing shift of catching tunas to swordfish by Taiwanese longline fleets, the increasing number of longline fleets operations from various nations (e.g. Indonesia, Australia, La

\footnotetext{
*Corresponding author: bramsetyadji@kkp.go.id
} 
Reunion, Seychelles and Mauritius), and arrival of longline fleets from the Atlantic Ocean (e.g. Portugal, Spain and United Kingdom). In recent years (2013-2017), Indonesian fleets are responsible for approximately $20 \%$ of the total catch of swordfish in the Indian Ocean ( 8,000 MT), followed by Taiwan (17\%), Sri Lanka (12\%) and Spain (12\%) [2]. However, the total catch was revised to just under $\sim 3,000 \mathrm{MT}(9 \%)$ due to the refining methodology on catch estimation provided by the IOTC secretariat [3]. In addition, the revision also aligned with the impact of Ministerial Regulation No. 56/2014 and No. 57/2014 about the moratorium on foreign fishing vessels and prohibition of transshipment at sea within Indonesia national jurisdiction, which resulted in a significant reduction of longline vessel operations from 584 in 2015 to 271 in 2016. Despite the abundant catches, swordfish is still considered as a bycatch of the Indonesian commercial tuna longline fishery [4].

The current population of swordfish in the Indian Ocean is considered neither overfished or a subject to overfishing [2]. Nevertheless, the most recent catches (31,407 $\mathrm{t}$ in 2016) were at the Maximum Sustainable Yield (MSY) level (31,590 t). Hence, due to the uncertainty from the Indonesian catch, in 2017 the number should not have been above MSY level. The estimation of relative abundance indices (e.g., standardized catch-per-unit-of-effort/CPUE) signifies important information concerning the status of fisheries stocks [5]. Furthermore, those indices are necessary to run simple models, and they are also used as auxiliary data in more detailed stock assessment models [6]. Standardizing CPUE for species with a low number of catch and a substantial proportion of zero catch, such as billfishes, are needed to consider more inclusive models to analyze the proportions of zeros and the positive catch rates separately (i.e., delta distribution models) or use of zero-inflated models [5]. However, in many cases, longline data are compatible with two parts or hurdle models because they accommodate more flexibility than single-part distributions, particularly for rare and nontargeted species [7].

Our analytical objective was to investigate how the data-limited of swordfish fishery can construct a fairly robust relative abundance indices amid the "spatial gap" of the existing dataset for standardized CPUE in the eastern Indian Ocean (e.g., Japanese and Taiwanese longline dataset). We believe the results are valuable as an important information to assess the status of swordfish in the Indian Ocean.

\section{Materials and Methods}

\subsection{Data collection}

This research analyzed the data gathered by the Indonesian scientific observer on commercial tuna longline vessels, which are mainly situated in Benoa Fishing Port, Bali. The observation program started in 2005 through an Australia-Indonesia collaboration (Project FIS/2002/074 of Australian Centre for International Agricultural Research), and since 2010 it has been conducted by the Research Institute for Tuna Fisheries (RITF Indonesia).

The dataset included information concerning the number of fishes caught by species, the total number of hooks, the number of Hooks Between Floats (HBF), the start time of the set, soak time, and geographic position (latitude and longitude) where the longlines deployed into the water. The response variable in the models was the catch of swordfish in number (N). Year and quarter were used as a categorical (factor) explanatory variables. Additional information was used as explanatory variables as follows:

- Year: analyzed between 2005 and 2016;

- A quarter of the year: 4 categories: 1 = January to March, $2=$ April to June, $3=$ July to September, 4 = October to December; 
- Area: treated as a categorical variable, describing spatial catch within and outside the Indonesian EEZ. We also use latitude and longitude as additional quantitative variables.

- Start time of the set: treated as a quantitative variable, the values were rounded to the nearest integer;

- Soak time: calculated as the time elapsed between the start of setting up the longline and the start of hauling. Soak time in the model was treated as a continuous variable. Thus the value was rounded to the nearest integer;

- Moon phase (29.5 days): categorized into two periods, as light and dark, and assumed the demilunes (first/last quarters), and waning gibbous and full moon as light period; new moon and crescent as dark period [8];

- The number of hooks between floats: treated as a quantitative variable instead of factor.

\subsection{CPUE standardization}

We considered six GLM models for modeling the number of swordfishes for modeling the nominal catch (number of fish) as a response variable while effort was included in the models as an offset caught. These models are Poisson (P) and Negative Binomial (NB), which we refer to as the standard models, Zero-Inflated Poisson (ZIP), Zero-Inflated Negative Binomial (ZINB), Poisson Hurdle (PH), and Negative Binomial Hurdle (NBH) models.

We applied a forward approach to select the explanatory variables and the order included in the full model. The first step was to fit simple models with one variable at a time. The variable included in the model with the lowest residual deviance was selected as a start. As the second step, the model with the selected variable then received other variables one at a time, and the model with the lowest residual deviance was again selected. The same procedure was extended until the residual deviance did not decrease as new variables added to the previously selected model. Finally, all main effects and first-order interactions were analyzed and a backward procedure based on Akaike Information Criterion (AIC) [9] and Bayesian Information Criterion (BIC) [10] was used to select the final models for the six approaches. We also relied on AIC and BIC to compare these models.

The qualities of the fittings were assessed by comparing the observed frequency distributions of the number of fish caught to the predicted frequency distribution, as calculated using the selected models. Kolmogorov-Smirnov test was used to assess whether the difference between the two distributions (observed and predicted) were significant. Maps were produced using QGIS version 2.14 [11] and the statistical analyses were carried out using R software version 3.5.3 [12], particularly the package pscl [13], lsmeans [14], MASS [15], Hmisc [16], and statmod [17].

\section{Results}

\subsection{Descriptive Catch Statistic}

RITF scientific observers recorded catch and operational data at sea following Indonesian tuna longline commercial vessels from 2005-2016. The dataset contained 100 trips, 2565 sets, 2797 days-at-sea, and more than 3.3 hooks deployed, respectively (Table 1). 
Table 1. Summary of the observed fishing effort from Indonesian tuna longline fishery during 20052016. The results are pooled and presented by year of observation unit. Operational parameters are means (upper entries) and standard deviations (lower parenthetical entries).

\begin{tabular}{|c|c|c|c|c|c|c|c|c|}
\hline Year & Trips & Sets & Days at Sea & Total Hooks & \multicolumn{3}{|c|}{ Hooks per Set } & \multicolumn{2}{c|}{ Hooks per Float } \\
\hline 2005 & 9 & 108 & 117 & 157,065 & $1,454.31$ & $(151.8)$ & 18.6 & $(1.5)$ \\
\hline 2006 & 13 & 401 & 401 & 577,243 & $1,439.51$ & $(214.9)$ & 11.2 & $(3.9)$ \\
\hline 2007 & 13 & 265 & 258 & 406,135 & $1,532.58$ & $(326.5)$ & 14.0 & $(4.4)$ \\
\hline 2008 & 15 & 370 & 404 & 483,662 & $1,307.19$ & $(385.9)$ & 13.0 & $(4.5)$ \\
\hline 2009 & 13 & 283 & 288 & 323,042 & $1,141.49$ & $(234.7)$ & 12.1 & $(4.9)$ \\
\hline 2010 & 6 & 165 & 152 & 220,394 & $1,335.72$ & $(457.5)$ & 13.6 & $(5.2)$ \\
\hline 2011 & 3 & 105 & 111 & 110,384 & $1,051.28$ & $(173.9)$ & 12.0 & - \\
\hline 2012 & 8 & 198 & 192 & 290,265 & $1,465.98$ & $(559.1)$ & 14.1 & $(2.3)$ \\
\hline 2013 & 7 & 225 & 198 & 252,919 & $1,124.08$ & $(210.4)$ & 12.7 & $(2.1)$ \\
\hline 2014 & 5 & 167 & 265 & 193,740 & $1,160.12$ & $(176.9)$ & 15.0 & $(2.0)$ \\
\hline 2015 & 5 & 148 & 241 & 172,463 & $1,165.29$ & $(145.2)$ & 14.1 & $(3.2)$ \\
\hline 2016 & 3 & 130 & 170 & 175,868 & $1,352.83$ & $(209.0)$ & 11.3 & $(3.3)$ \\
\hline
\end{tabular}

The spatial data distributed mainly in the eastern Indian Ocean with most of the observations were conducted in the area south of Indonesian waters, between $0^{\circ}-35^{\circ} \mathrm{S}$ and $75^{\circ}-125^{\circ} \mathrm{E}$ (Fig. $1)$.

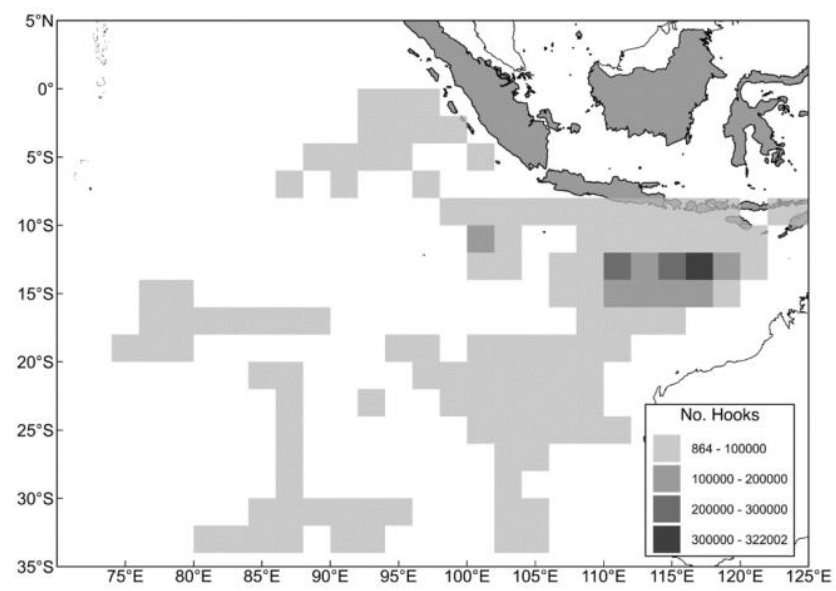

Fig 1. The distribution of the Indonesia observer data used in this SWO CPUE standardization. The effort is represented in $2 \times 2$ grids with darker and lighter colors representing areas with more and less effort respectively in the total number of hooks.

\subsection{CPUE data characteristics}

SWO nominal CPUE series is presented in Fig. 2. In general, the catches of SWO during the last decade were highly variable, but showing an increasing trend. The lowest CPUE recorded was in $2011(0.12 \pm 0.04)$, while the highest was in $2009(0.53 \pm 0.06)$. On the other hand, the proportion of zero catch per set for SWO was also high, around $71.07 \%$. Varying annually between a minimum of $0.61 \pm 0.03$ in 2012 and a maximum of $0.82 \pm 0.04$ in 2005 (Fig. 3). 


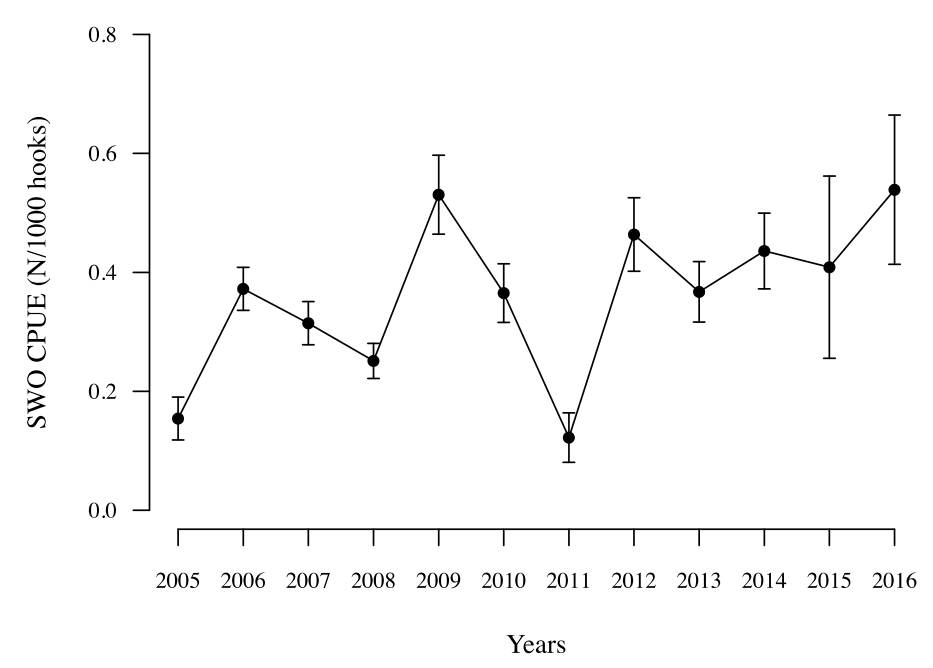

Fig 2. Nominal CPUE series (N/1000 hooks) for SWO in the Indonesia data, between 2005 and 2016. The error bars refer to the standard errors.

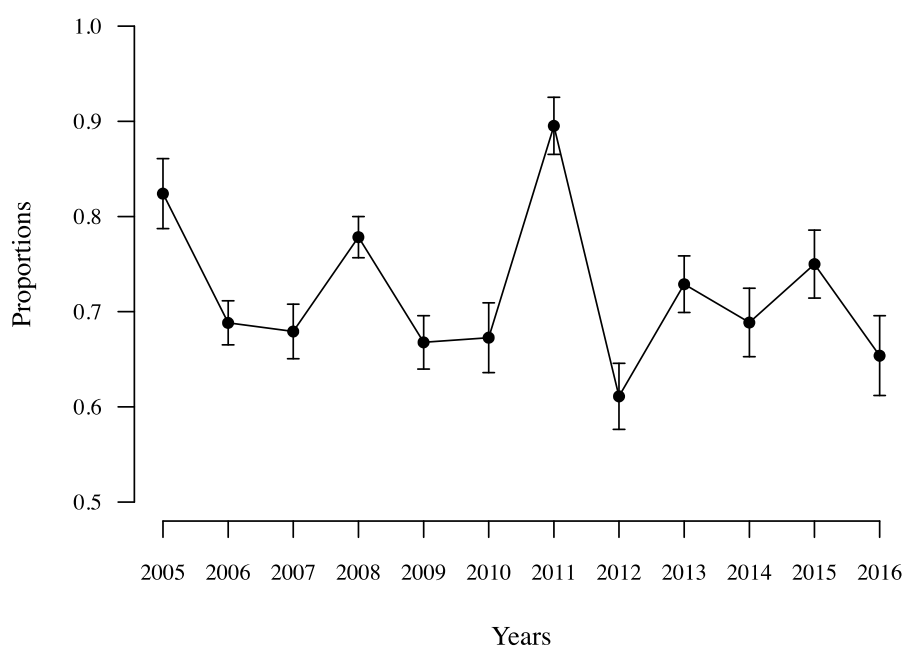

Fig 3. The proportion of zero SWO catches per set and per year, in the Indonesia data, between 2005 and 2016. The error bars refer to the standard errors.

\subsection{CPUE standardization}

The number of parameters (k), AIC, BIC, the logarithm of the likelihood (logLik), number of predicted zero catches, and $p$ values of Kolmogorov-Smirnov test as calculated using six model structures (P, NB, ZIP, ZINB, HP, and HNB are shown in Table 2. The overall logarithm of likelihood of zero-inflated and particularly hurdle models was high, but they will be more complex if many parameters involved. The number of zero catches in the database was 1823 . The negative binomial model was selected because it holds the lowest value in both AIC and BIC (4330.40 and 4599.47, respectively). 
Table 2. Summary of indicators as calculated using six model structures: Poisson (P), Negative Binomial (NB), Zero-inflated with Poisson (ZIP), Zero-inflated with Negative Binomial (ZINB), Hurdle with Poisson (HP), and Hurdle with Negative Binomial (HNB). The terms in the column at left indicate: number of parameters (k), Akaike (AIC) and Bayesian (BIC) Information Criteria, the

logarithm of the likelihood (logLik), number of predicted zero catches (zero), and $p$ values as calculated using a Kolmogorov-Smirnov test.

\begin{tabular}{|l|r|r|r|r|r|r|}
\hline \multirow{2}{*}{ Parameters } & \multicolumn{7}{|c|}{ Model Structures } \\
\cline { 2 - 7 } & \multicolumn{1}{|c|}{ P } & \multicolumn{1}{c|}{ NB } & \multicolumn{1}{c|}{ ZIP } & \multicolumn{1}{c|}{ ZINB } & \multicolumn{1}{c|}{ HP } & \multicolumn{1}{c|}{ HNB } \\
\hline K & 75 & 45 & 44 & 46 & 90 & 88 \\
\hline AIC & 4470.02 & 4330.40 & 4475.18 & 4400.26 & 4353.23 & 4340.54 \\
\hline BIC & 4908.72 & 4599.47 & 4732.55 & 4669.33 & 4879.67 & 4855.28 \\
\hline LogLIk & -2160.01 & -2119.20 & -2193.59 & -2153.13 & -2086.62 & -2081.27 \\
\hline Zero & 1712 & 1780 & 1815 & 1830 & 1823 & 1823 \\
\hline p.value & 0.016 & 0.864 & 0.999 & 1.000 & 1.000 & 1.000 \\
\hline
\end{tabular}

Several explanatory variables tested for the SWO CPUE standardization were significant and contributed significantly in explaining the part of the deviance. Some interactions were also significant and therefore were included in the final model. On the final model, the factors that majorly contributed to the deviance were the Start_Set, followed by Year, HBF, Moon, Quarter, Area, Long, Lat and the interactions (Table 3). In terms of the model validation, the residual analysis, including the residual distribution along with the fitted values, the QQ plots, and the residuals histograms, showed that the model was adequate with no major outliers or trends in the residuals (Fig. 4).

Table 3. Deviance table of the parameters used for SWO CPUE standardization, using a negative binomial model (NB). Each parameter indicated the degrees of freedom (Df), the deviance (Dev), the residual degrees of freedom (Resid Df), the residual deviance (Resid. Dev), the Chi-square test statistic and the significance ( $\mathrm{p}$-value).

\begin{tabular}{|l|r|r|r|r|r|l|}
\hline & Df & Deviance & Resid. Df & Resid. Dev & Pr(>Chi) & \\
\hline NULL & & & 2563 & 2420.8 & & \\
\hline Year & 11 & 98.711 & 2552 & 2322.1 & $3.21 \mathrm{E}-16$ & $* * *$ \\
\hline Start_Set & 1 & 129.246 & 2551 & 2192.8 & $2.20 \mathrm{E}-16$ & $* * *$ \\
\hline HBF & 1 & 35.854 & 2550 & 2156.9 & $2.13 \mathrm{E}-09$ & $* * *$ \\
\hline Moon & 3 & 35.166 & 2547 & 2121.8 & $1.12 \mathrm{E}-07$ & $* * *$ \\
\hline Soak_Time & 1 & 11.575 & 2546 & 2110.2 & 0.0006686 & $* * *$ \\
\hline Quarter & 3 & 17.351 & 2543 & 2092.9 & 0.0005985 & $* * *$ \\
\hline Latt & 1 & 0.005 & 2542 & 2092.8 & 0.9430643 & \\
\hline Long & 1 & 0.025 & 2541 & 2092.8 & 0.8747718 & \\
\hline Area & 1 & 0.783 & 2540 & 2092.0 & 0.3762931 & \\
\hline Start_Set:Soak_Time & 1 & 5.347 & 2539 & 2086.7 & 0.0207573 & $*$ \\
\hline Start_Set:Long & 1 & 4.118 & 2538 & 2082.6 & 0.0424273 & $*$ \\
\hline HBF:Moon & 3 & 15.644 & 2535 & 2066.9 & 0.0013415 & $* *$ \\
\hline HBF:Latt & 1 & 0.807 & 2534 & 2066.1 & 0.3690882 & \\
\hline HBF:Long & 1 & 10.096 & 2533 & 2056.0 & 0.0014857 & $* *$ \\
\hline HBF:Area & 1 & 2.321 & 2532 & 2053.7 & 0.1276281 & \\
\hline Soak_Time:Quarter & 3 & 9.955 & 2529 & 2043.8 & 0.0189515 & $*$ \\
\hline Soak_Time:Long & 1 & 16.614 & 2528 & 2027.1 & $4.58 \mathrm{E}-05$ & $* * *$ \\
\hline Quarter:Latt & 3 & 27.117 & 2525 & 2000.0 & $5.56 \mathrm{E}-06$ & $* * *$ \\
\hline Quarter:Long & 3 & 38.143 & 2522 & 1961.9 & $2.64 \mathrm{E}-08$ & $* * *$ \\
\hline Latt:Long & 1 & 3.424 & 2521 & 1958.5 & 0.0642577 & $*$ \\
\hline Latt:Area & 1 & 7.825 & 2520 & 1950.6 & 0.0051539 & $* *$ \\
\hline Long:Area & 1 & 3.310 & 2519 & 1947.3 & 0.0688788 & $*$ \\
\hline
\end{tabular}

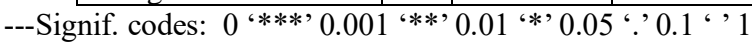



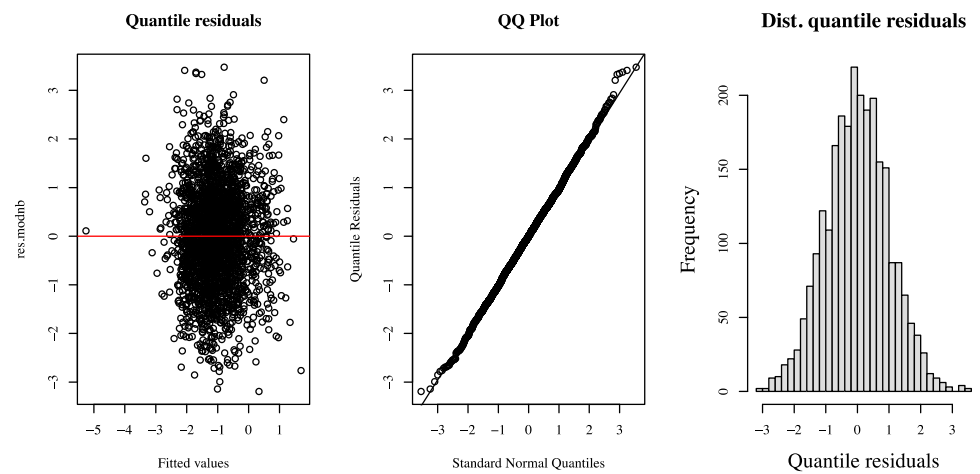

Fig. 4. Residual analysis for the final SWO CPUE standardization model for the data in Indonesia during 2005 and 2016. In the plot, it is presented the histogram of the distribution of the residuals (right), the QQPlot (middle) and the residuals along with the fitted values on the log scale (left).

The final standardized SWO CPUE index (N/1000 hooks) from Indonesian data in the eastern Indian Ocean between 2005 and 2016 is shown in Figure 5 and Table 4. The trends were relatively similar to the nominal series, but with smoother peaks. In general, there were no noticeable trends, with the series varying along the period.

Table 4. Nominal and standardized CPUEs (N/1000 hooks) of SWO using the Indonesia data in the eastern Indian Ocean. The point estimates, $95 \%$ confidence intervals, and the standard deviation (SD) of the standardized index are presented, including the nominal CPUE values.

\begin{tabular}{|l|r|r|r|r|r|}
\hline \multirow{2}{*}{ Year } & Nominal & \multicolumn{3}{|c|}{ Standardized CPUE Index (N/1000 Hooks) } \\
\cline { 3 - 6 } & CPUE & Estimate & \multicolumn{1}{c|}{ sd } & Lower CI (95\%) & Upper CI (95\%) \\
\hline 2005 & 0.154 & 0.185 & 0.054 & 0.104 & 0.328 \\
\hline 2006 & 0.372 & 0.267 & 0.048 & 0.187 & 0.381 \\
\hline 2007 & 0.314 & 0.190 & 0.043 & 0.122 & 0.294 \\
\hline 2008 & 0.251 & 0.193 & 0.039 & 0.130 & 0.286 \\
\hline 2009 & 0.531 & 0.365 & 0.073 & 0.247 & 0.540 \\
\hline 2010 & 0.365 & 0.272 & 0.058 & 0.179 & 0.412 \\
\hline 2011 & 0.122 & 0.146 & 0.046 & 0.079 & 0.271 \\
\hline 2012 & 0.464 & 0.363 & 0.078 & 0.238 & 0.554 \\
\hline 2013 & 0.367 & 0.353 & 0.065 & 0.246 & 0.506 \\
\hline 2014 & 0.436 & 0.371 & 0.075 & 0.250 & 0.550 \\
\hline 2015 & 0.261 & 0.175 & 0.042 & 0.110 & 0.279 \\
\hline 2016 & 0.539 & 0.354 & 0.071 & 0.239 & 0.525 \\
\hline
\end{tabular}




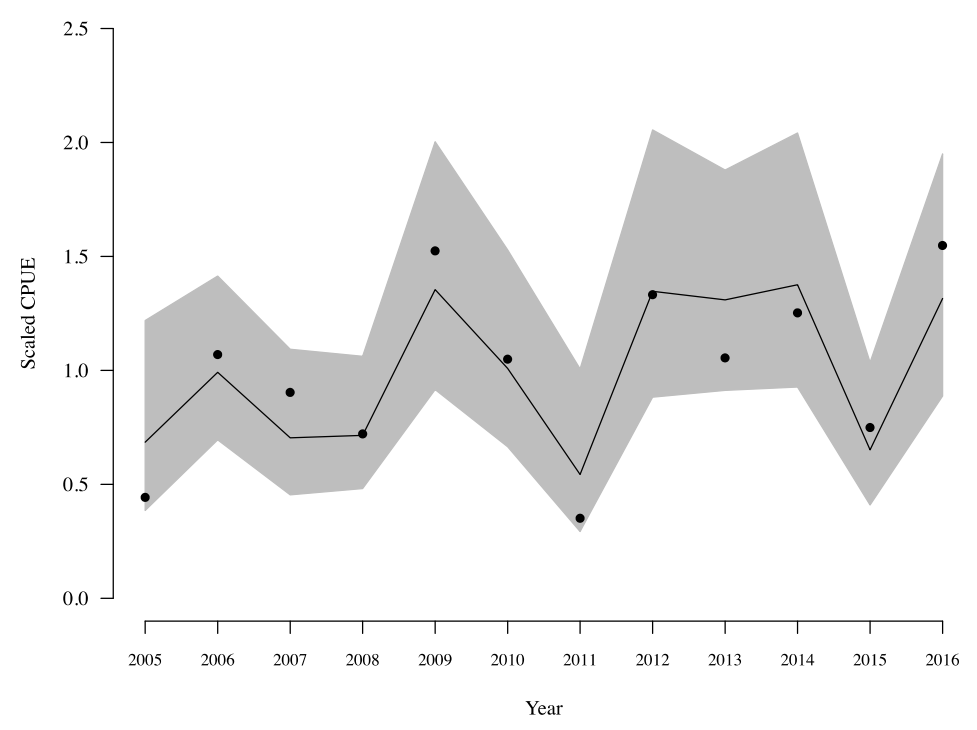

Fig. 5. Standardized CPUE series for SWO from Indonesia data using a negative binomial model, between 2005 and 2016. The solid lines refer to the standardized index with the $95 \%$ confidence intervals, and the dots represent the nominal CPUE series. Both series are scaled by their means.

\section{Discussion}

Simple negative binomial distribution worked better for data that contained a lot number of zero observations, as shown in this study, for example. However, although the final model involved a lot of interaction among variables, it is unlikely to cause overfitting. The series, overall, showed a positive trend with high variations occurred toward the end of the series. It is probably be affected by a lot of zero catch per set in the data. Thus, the nominal CPUE is highly influenced by possibly non-targeting fleets and biased the calculation. A few workarounds, can be done in order to reduce unwanted zero catches, i.e. using core area [18], which is a $1 \times 1$ degree-based catch block with a minimum constant catch for at least 6 years (doesn't need to be consecutively) could improve the proportion of zero catch from $93 \%$ to $58 \%$. Other solutions, such as: incorporating random effect into General Linear Mixed Model (GLMM) [19], using a more complex model, i.e., delta-lognormal [20] or applying to smooth in the zero-inflated negative binomial model [21] could be considered. Inclusion of environmental factors, i.e., Sea Surface Temperature (STT) also highly correlated to CPUE of swordfish [22,23].

The high proportion of zero catch per set that occurred during observation may relate to low productivity areas surrounding the southeastern Indian Ocean. High swordfish catch rates recorded by Spanish, Portuguese, Japanese, and Taiwanese fleets are mostly concentrated in the western Indian Ocean and northeastern Indian Ocean [19,23-25]. While, south of Java, Bali and Nusa Tenggara waters are well-known as southern bluefin tuna spawning ground, instead [26]. Swordfish is a by-product from tuna longline fishery targeting yellowfin, albacore, and bigeye tuna. Thus, a large proportion of sets $(\sim 80 \%)$ were conducted at dawn. While most swordfish-targeted fishery mostly commenced sets at night [27], following their diel vertical migration [28].

Overall, the model could only explain $\sim 20 \%$ of the variables; the interaction did play a part but only contributed to $\sim 6 \%$ improvement. Start of sets (Start_Set) was the main driven 
factor, as it reduces the residual deviance substantially, followed by Year, hooks between floats (HBF) and moon phase (Moon), respectively. On the other hand, swordfish catch rates were not influenced by spatial influence, such as latitude and longitude. Little are confirmed that setting time is affecting the variability of swordfish CPUE since most assessments are obtained from logbook data, but Setyadji et al. [29] found that it was not an influential variable and was dropped from the model, at least in the black marlin (Makaira nigricans) case. A plausible scenario, although most of the sets were conducted at dawn, the probability of swordfish caught was higher at night, despite the small margin between two-time frames ( $26 \%$ and $35 \%$ respectively). HBF mainly correlated with set depth which reflects targeting strategy [30] and may vary spatially according to different HBF set up [31]. It also an integral variable to the CPUE standardization model when available [19,20]. With deep longline configuration, it is more likely swordfish to be caught during night sets compared to daylight (30\% and $17 \%$, respectively). Swordfish mainly caught during the first and last quarter of the lunar phase in longline fishery [32] and during the new moon or dark period in gillnet fishery [8]. By contrast, soak time (Soak_Time) and a quarter were also important but only explained an inconsequential portion of CPUE variability. Further, Carruthers et al. [27] also found that both soak time and various depth temperature did not affect swordfish catch rates. Instead, it highly correlated with the catch of blue shark (Prionace glauca).

Although the model fits very well, and a closer look on the standardized trend, it describing similar compared to Japanese and Taiwanese at the relatively same period (20052015) and area (southeast Indian Ocean) [19,20]. Therefore, In order to get a clear picture of the population of swordfish in the Indian Ocean, particularly in the southeastern area, a joint CPUE initiative as it did with yellowfin and albacore fishery $[33,34]$ should be a priority.

Most of the catch and effort data are usually obtained from a fishery-dependent source, such as logbook, however, in this study, fishery-independent data (scientific observer) was accommodated instead since the application of logbook system has not met the satisfactory requirement for analysis, at least in the last two decades. Exploratory surveys or scientific observer data usually more reliable since it conducted by competent scientists or technicians. Nevertheless, the substantial cost involved could be a barrier to further development. A continuation of such a program is a necessity, focusing on more spatial coverage and quantity of effort observed (at least $5 \%$ of total effort).

Both AIC and BIC suggested that the simple negative binomial (NB) model is the best in determining the abundance index for swordfish. On the overall, the trends were relatively similar to the nominal series, but with smoother peaks. In addition, there was a tendency of slightly positive trends in the last decade, with the series varying throughout the period.

In order to get a more robust analysis, given the constraints on spatial coverage, exploring another model, such as the delta-lognormal model and advanced data screening to reduce the proportion of zero-catch-per-set could be a thing to consider in the future.

The authors wish to thank the scientific observers who performed invaluable roles in fisheries data collection as part of the Australian Centre for International Agricultural Research Project (ACIAR) FIS/2002/074, and subsequently as observers of Research Institute for Tuna Fisheries (2011 and onwards). We would also like to show our gratitude to Humber A. Andrade, Rui Coelho, and Philippe Sabarros for their valuable comments on the manuscript.

\section{References}

1. G. Tserpes and N. Tsimenides, Fishery Bulletin 93, 594 (1995)

2. IOTC-WPB16, Report of the 16th Session of the IOTC Working Party on Billfish (Indian Ocean tuna Commission (IOTC), Cape Town, South Africa, 2018), p. 97 
3. IOTC-WPDCS14, Report of the 14th Session of the IOTC Working Party on Data Collection and Statistics. (Indian Ocean tuna Commission (IOTC), Victoria, Seychelles, 2018), p. 71

4. B. Setyadji and B. Nugraha, Jurnal Penelitian Perikanan Indonesia 18, 43 (2012)

5. M. N. Maunder and A. E. Punt, Fisheries Research 70, 141 (2004)

6. E. Rodríguez-Marín, H. Arrizabalaga, M. Ortiz, C. Rodríguez-Cabello, G. Moreno, and L. T. Kell, ICES Journal of Marine Science 60, 1216 (2003)

7. A. F. Zuur, E. N. Ieno, and A. A. Saveliev, Zero Inflated Models and Generalized Linear Mixed Models with R (Highland Statistics Limited, 2012)

8. O. Akyol, Turkish Journal of Fisheries and Aquatic Sciences 13, 355 (2013)

9. H. Akaike, IEEE Transactions on Automatic Control 19, 716 (1974)

10. G. Schwarz, The Annals of Statistics 6, 461 (1978)

11. QGIS Developer Team, QGIS Geographic Information System (Open Source Geospatial Foundation Project, 2018)

12. R Core Team, $R$ : A Language and Environment for Statistical Computing (R Foundation for Statistical Computing, Vienna, Austria, 2018)

13. A. Zeileis, C. Kleiber, and S. Jackman, Journal of Statistical Software 27, 1 (2008)

14. R. Lenth, Emmeans: Estimated Marginal Means, Aka Least-Squares Means (2018)

15. W. N. Venables and B. D. Ripley, Modern Applied Statistics with S, Fourth (Springer, New York, 2002)

16. F. E. Harrell Jr., C. Dupont, and Others, Hmisc: Harrell Miscellaneous (2018)

17. G. Giner and G. K. Smyth, ArXiv Preprint ArXiv:1603.06687 (2016)

18. H. Yokoi, S. Semba, K. Satoh, and N. Tsutomu, Paper Presented on 14th Working Party on Billfish, Victoria, Seychelles, 6-10 September 2016, IOTC-2016-WPB1419_Rev1 17 (2016)

19. H. Ijima, Paper Presented on 15th Working Party on Billfish, San Sebastian, Spain, 1014 September 2017, IOTC-2017-WPB15 32 (2017)

20. S.-P. Wang, Paper Presented on 15th Working Party on Billfish, San Sebastian, Spain, 10-14 September 2017, IOTC-2017-WPB15-17 28 (2017)

21. M. Minami, C. E. Lennert-Cody, W. Gao, and M. Roman-Verdesoto, Fisheries Research 84, 210 (2007)

22. Y.-J. Chang, C.-L. Sun, Y. Chen, S.-Z. Yeh, and G. Dinardo, International Journal of Remote Sensing 33, 7523 (2012)

23. K.-W. Lan, K. Evans, and M.-A. Lee, Climatic Change 119, 63 (2013)

24. R. Coelho, P. G. Lino, and D. Rosa, Paper Presented on 15th Working Party on Billfish, San Sebastian, Spain, 10-14 September 2017, IOTC-2017-WPB15-14 17 (2017)

25. J. Fernández-Costa, B. García-Cortés, A. Ramos-Cartelle, and J. Mejuto, Paper Presented on 15th Working Party on Billfish, San Sebastian, Spain, 10-14 September 2017, IOTC-2017-WPB15-16 12 (2017)

26. J. H. Farley, J. P. Eveson, T. L. Davis, R. Andamari, C. H. Proctor, B. Nugraha, and C. R. Davies, PloS One 9, e96392 (2014)

27. E. H. Carruthers, J. D. Neilson, and S. C. Smith, Fisheries Research 108, 112 (2011) 
28. B. Setyadji and H. Hartaty, ILMU KELAUTAN: Indonesian Journal of Marine Sciences 21, 9 (2016)

29. B. Setyadji, H. A. Andrade, and C. H. Proctor, Turkish Journal of Fisheries and Aquatic Sciences 19, 119 (2018)

30. S. D. Hoyle, A. D. Langley, and R. A. Campbell, A Paper Presented at Scientific Committee Tenth Regular Session, Majuro, Republic of the Marshall Islands 6-14 August 2014, WCPFC-SC10-2014/ SA-IP-10 22 (2014)

31. S. D. Hoyle and H. Okamoto, Pohnpei, Federated States of Micronesia 201, 129 (2011)

32. F. Poisson, J.-C. Gaertner, M. Taquet, J.-P. Durbec, and K. Bigelow, Fishery Bulletin 108, 268 (2010)

33. S. D. Hoyle, D. N. Kim, S. I. Lee, T. Matsumoto, K. Satoh, and Y.-M. Yeh, A Paper Presented at 18th Working Party on Tropical Tuna, Victoria, Seychelles, 5-10 November 2016, IOTC-2017-WPTT19-32 52 (2016)

34. S. D. Hoyle, E. Chassot, D. Fu, D. N. Kim, S. I. Lee, T. Matsumoto, K. Satoh, S.-P. Wang, and T. Kitakado, A Paper Presented at 7th Working Party on Temperate Tuna (Data Preparatory Meeting), Kuala Lumpur, Malaysia, 14-17 January 2019, IOTC2019-WPTmT07(DP)-19 45 (2019) 